\title{
Orthodontic repositioning of traumatically intruded permanent incisors - A report of three cases
}

SADJ February 2021, Vol. 76 No. 1 p14 - p21

H Singh ${ }^{1}$, M Mittal ${ }^{2}$, P Sharma ${ }^{3}$, A Kumar ${ }^{4}$, P Kapoor ${ }^{5}$

\begin{abstract}
Intrusive luxation of permanent teeth is one of the most serious traumatic dental injuries involving damage to the gingival tissue, periodontal ligament, cementum, bone and to the neurovascular supply of the pulp. In addition to disruption of normal tooth development and eruption, it can also lead to pulpal necrosis, root resorption and marginal bone loss. Based on the extent/severity, intrusion maybe classified into mild $(<3 \mathrm{~mm})$, moderate $(3-6 \mathrm{~mm})$ and severe (>6 mm).
\end{abstract}

Available techniques for managing intrusive luxation include a wait-and-watch approach to allow for spontaneous re-eruption, orthodontic traction and surgical repositioning. The type of treatment approach employed depends upon the stage of root development, severity of intrusive luxation and the presence or absence of alveolar fractures.

It is difficult to predict reliable outcomes with these approaches, since the presence of variables such as the severity of intrusion, associated crown/root fracture, stage of root development and presence of alveolar fractures may alter the prognosis.

The present article presents a series of three cases with intrusive luxation of permanent incisors successfully treated using an interdisciplinary approach involving orthodontic traction along with endodontic rehabilitation.

Author affiliations:

1. Harpreet Singh: BDS, MDS, Associate Professor, Department of Orthodontics, ESIC Dental College, Rohini, Delhi, India.

2. Meenu Mittal: $B D S, M D S$, Professor, Department of Paediatric Dentistry, ESIC Dental College, Rohini, Delhi, India.

3. Poonam Sharma: BDS, MDS, Professor, Department of Orthodontics, ESIC Dental College, Rohini, Delhi, India.

4. Ashok Kumar: BDS, MDS, Associate Professor, Department of Paediatric Dentistry, ESIC Dental College, Rohini, Delhi, India.

5. Pranav Kapoor: BDS, MDS Professor, Department of Orthodontics, ESIC Dental College, Rohini, Delhi, India.

Corresponding author: Meenu Mittal

Professor, Department of Paediatric Dentistry, ESIC Dental College,

Rohini, Delhi, India.

Email: meenu20feb@gmail.com

Author contributions:

1. Harpreet Singh: Principal researcher, data collection, writing article - $20 \%$

2. Meenu Mittal: Principal researcher, data collection, writing article - $20 \%$

3. Poonam Sharma: Principal researcher $-20 \%$

4. Ashok Kumar: Writing article, advisor $-20 \%$

5. Pranav Kapoor: Writing article, advisor $-20 \%$

\section{Keywords}

Trauma, Intrusive luxation, orthodontic repositioning.

\section{INTRODUCTION}

Intrusive luxation of permanent teeth, comprising 0.3 to $2.0 \%$ of traumatic dental injuries in permanent dentition, ${ }^{1}$ is a severe dental injury that may cause extensive damage to the tooth and periodontium leading to the disruption of pulpal blood supply, crushing of periodontal ligament (PDL) with stripping away of cementum \& PDL, and trauma to the surrounding alveolar bone.

Intrusion may also result in a disruption in the normal tooth development and eruption, root resorption and marginal bone loss..$^{2-5}$ According to the Royal College of Surgeons of England, intrusion can be classified into mild $(<3 \mathrm{~mm})$, moderate $(3-6 \mathrm{~mm})$ and severe $(>6 \mathrm{~mm})$ types. ${ }^{6}$

Treatment modalities employed for intrusive luxation include: 1). Waitful watching for spontaneous re-eruption, 2). Surgical repositioning, or 3). Orthodontic repositioning. Since the contemporary literature has very few studies with a limited number of teeth involved, consensus regarding the outcome of the three treatment approaches is divided. Also, it is difficult to predict reliable outcomes with these treatment approaches since the presence of other variables such as severity of intrusion, associated crown/root fracture, stage of root development and presence of alveolar fracture may affect outcomes. ${ }^{7}$

There is a general agreement that intruded immature teeth should be allowed to erupt spontaneously. ${ }^{4,5,8}$ Variations in the recommended duration of waiting for spontaneous re-eruption exist in literature, with Al Badri et al. ${ }^{5}$ recommending 2 weeks, Stewart et al. ${ }^{8} 4$ weeks and International Association of Dental Traumatology (IADT) guidelines ${ }^{9}$ recommending a few weeks.

Spontaneous re-eruption following injury is unpredictable and relying on it can be over optimistic. ${ }^{7}$ In case of severe intrusion, delayed repositioning leaves the root in close contact with the alveolar bone which facilitates replacement root resorption and ankylosis. ${ }^{10,11,12}$ Moreover, associated complications such as external root resorption and loss of marginal bone support may further complicate the treatment progress. Incidence of pulp necrosis and root resorption in $63 \%$ of the teeth with open apex and $100 \%$ of teeth with closed apex has been reported with spontaneous re-eruption. ${ }^{10}$ 
Surgical repositioning is useful as it releases peri-radicular compression areas and removes the bacteria contaminated crown surface from its position in the socket. ${ }^{4}$ However, this approach, at the same time, leaves the intruded tooth with insufficient supporting alveolar bone and PDL, thereby resulting in an unaesthetic outcome. ${ }^{10}$

On the other hand, orthodontic repositioning is a more biologically sound method of repositioning the tooth, though it may not be superior to surgical repositioning. ${ }^{2,4,13}$ It offers the advantage of causing less marginal bone loss and facilitates better gingival and periodontal healing. Orthodontic repositioning is suggested when no spontaneous re-eruption is observed within few weeks or when a mature tooth has been intruded $3-7 \mathrm{~mm}$ or an immature tooth has been intruded more than $7 \mathrm{~mm}^{9}$

There is increasing evidence that orthodontic repositioning methods have improved outcomes, ${ }^{8,14}$ are more conservative, with a lower associated risk of ankylosis and other complications. ${ }^{10}$ Coronal migration of the periodontium occurs during slow orthodontic extrusion using light forces, as the tension of the periodontal fibers is delivered directly to the bone. Institution of orthodontic treatment also precludes the need for local anesthetic in an already fearful child.

If roots are fully formed or nearly so, root canal treatment is sought necessary in addition to both surgical and orthodontic repositioning.

The present case series demonstrates three cases of intrusive luxation of permanent incisors successfully managed by orthodontic repositioning, followed by endodontic therapy.

\section{CASE REPORT}

\section{Case 1}

A 9-year old boy reported to the Department of Paediatric Dentistry, ESIC Dental College, Delhi with an injury to the chin (Fig. 1). The patient gave a history of trauma to the chin following a fall from the stairs 2 weeks back. There was history of bleeding from oral cavity and difficulty in breathing.
Clinical examination revealed intrusion of $11,12,21$ \& 22 with anterior open bite, bunched up and painful gingival tissue in relation to $11 \& 21$ and obstruction of nasal airway because of encroachment of the nasal passage (Fig. 2).

The patient reported pain on percussion of the intruded upper right and left incisors. Radiographic examination including an IOPA X-ray and OPG revealed that the roots of the intruded teeth were more than $2 / 3^{\text {rd }}$ formed with an immature apex (Fig. 3A-C). The 3-dimensional conebeam computed tomography (CBCT) images confirmed that the dislocated 11 and 21 had penetrated the floor of the nasal cavity with resulting superior displacement of the fracture segment (Fig. 4). No associated crown or root fracture was observed. CBCT also revealed bilateral hypertrophy of inferior nasal turbinate and a right subcondylar fracture with medial displacement of fractured condylar head (Fig. 4).

It was decided to initiate orthodontic repositioning of the intruded teeth. Since the patient was in mixed dentition, a $2 \times 4$ appliance (0.022-inch $\times 0.028$-inch slot MBT prescription) was placed in the maxillary arch. Alignment and leveling was initiated using superelastic 0.012-inch Nickel-Titanium (NiTi) arch wire for a period of 4 weeks (Fig. 5A). Repositioning of incisors continued with light orthodontic force (approx. 40g) applied with the help of an elastomeric thread tied to two helices on a stabilizing $0.016 \times 0.022$-inch SS arch wire, which in turn prevented any arch deformation due to reactionary forces (Fig. 5B). The following sequence of arch wires was used to level the arch: 0.018-inch NiTi wire, $0.016 \times 0.022$-inch SS wire, followed by $0.018 \times$ 0.025 -inch SS wire during stabilization phase (Fig. 5C)

After 7 months of active treatment, debonding was done and a Hawley's appliance was delivered to be used as a retainer for one year (Figs. 6, 7 \& 8). The patient was satisfied with his clinical appearance at 4 years post injury follow up (Fig. 9A, B). However, the IOPA X-ray taken at 4 years follow-up revealed root resorption with narrowing of canals of $12 \& 22$ and periapical pathology in relation to $11 \& 21$ (Fig. 9C). Endodontic treatment was then performed in 11, 12, 21 \& 22 (Fig. 9D).

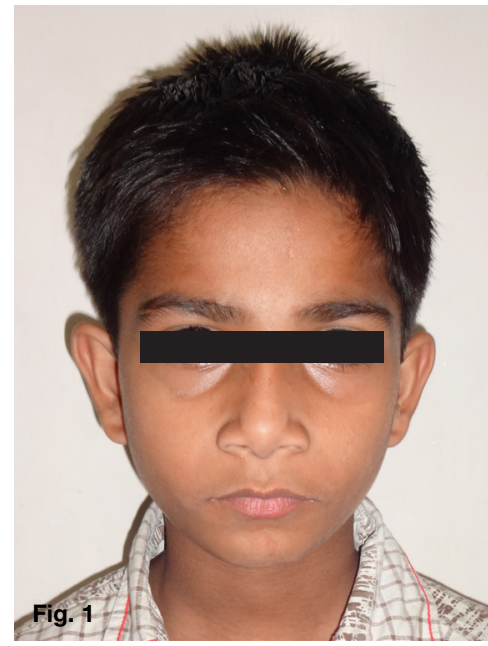

Figure 1. Case 1 - Pretreatment frontal photograph.
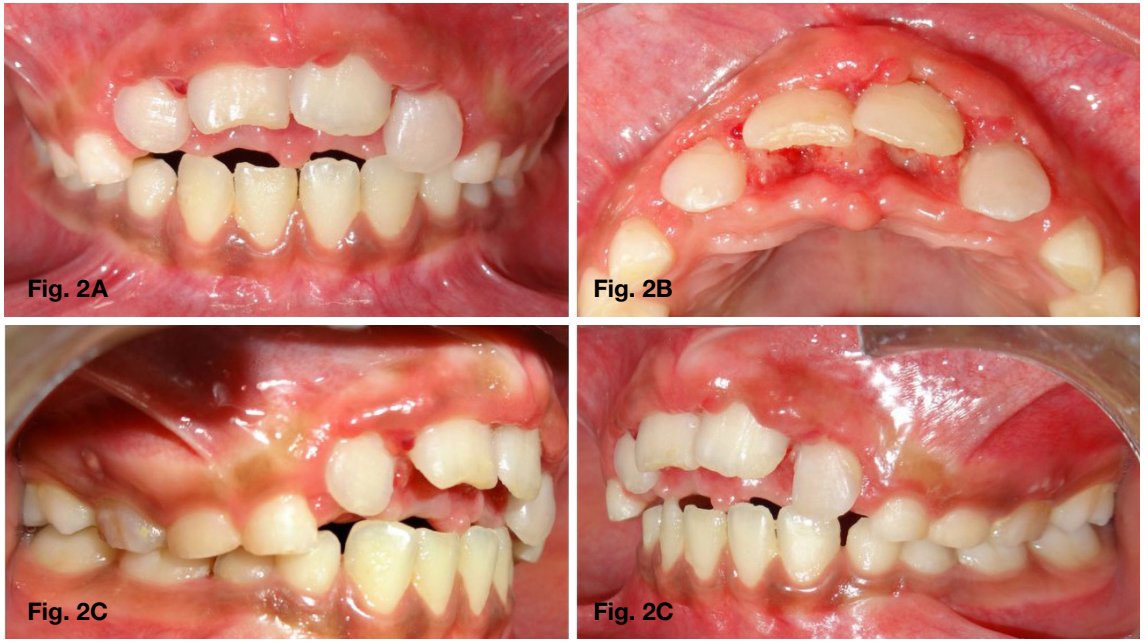

Figure 2. Case 1 - Pretreatment intraoral photographs showing traumatic intrusion of $11,12,21 \& 22$ with anterior open bite. 


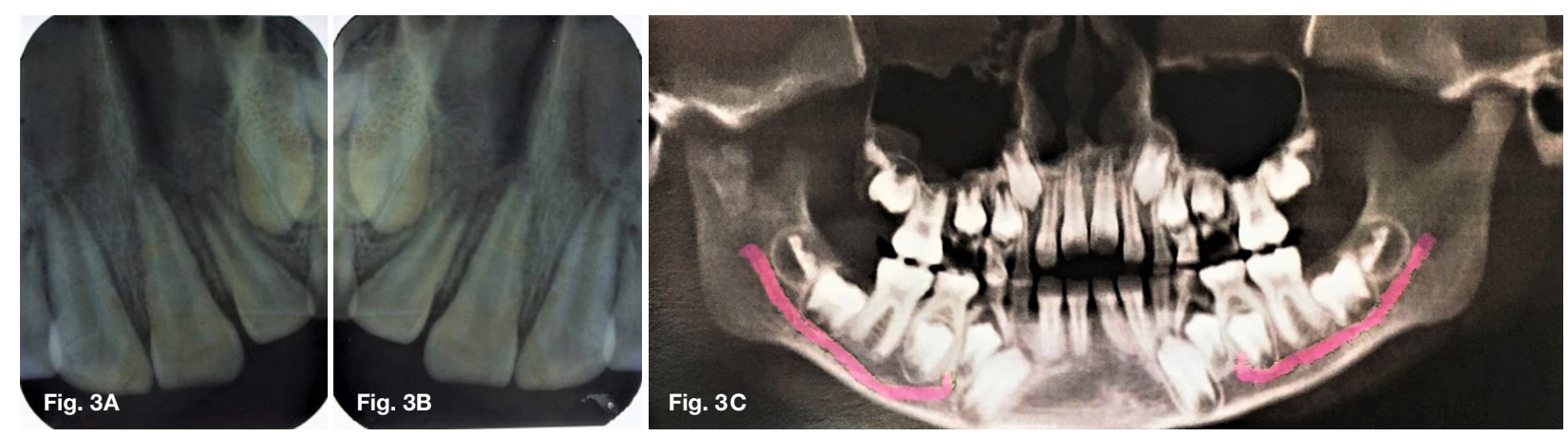

Figure 3. Case 1 - Pretreatment radiographs: A. IOPA of left central and lateral incisors. B. IOPA of right central and lateral incisors. C. OPG.
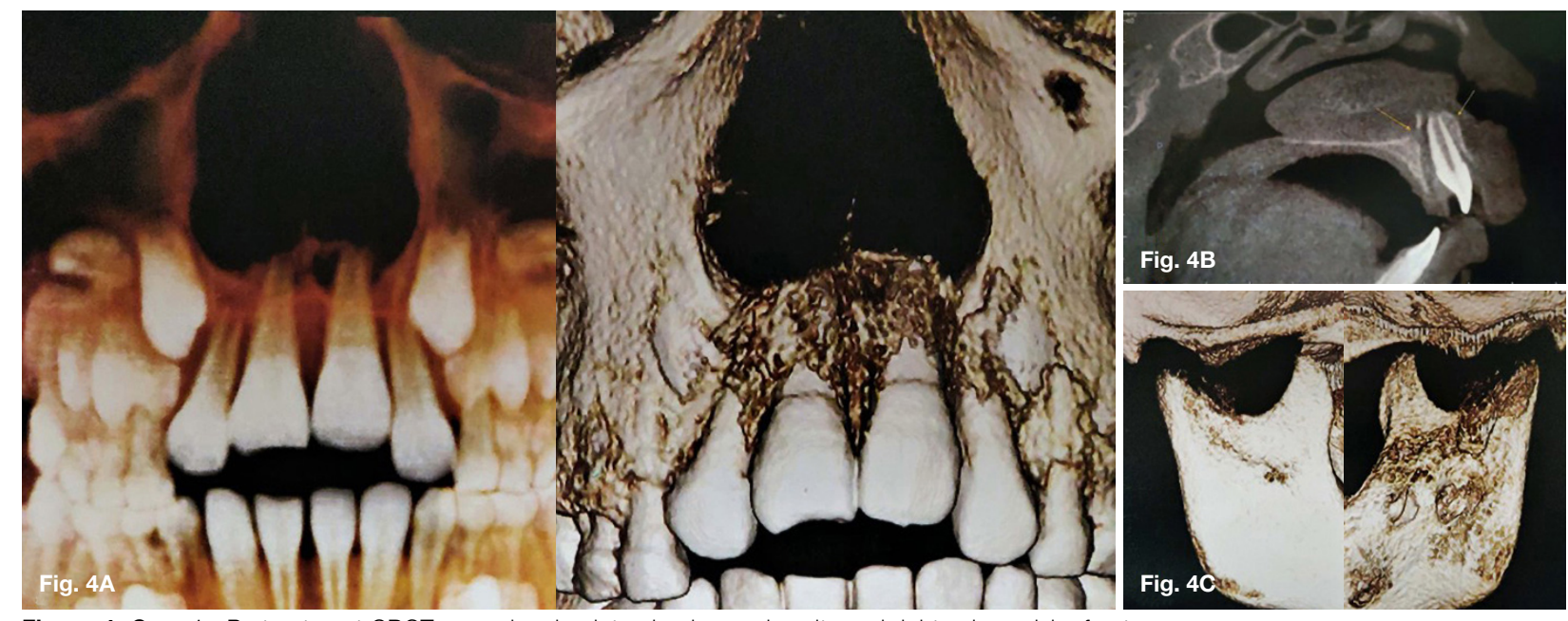

Figure 4. Case 1 - Pretreatment CBCT scan showing intrusion in nasal cavity and right subcondylar fracture.

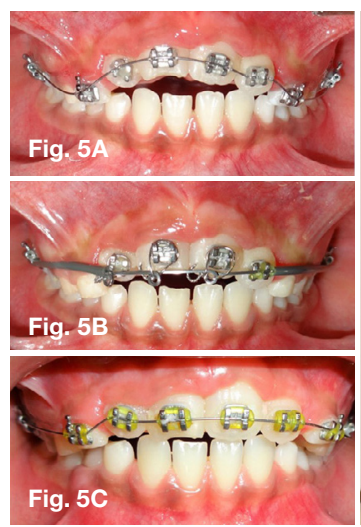

Figure 5. Case 1 - Treatment progress photographs: A. Alignment using 0.012" NiTi wire. B. Progression of incisors repositioning. C. Leveling in progress.

Figure 6. Case 1 - Post treatment photograph depicting good smile esthetics.

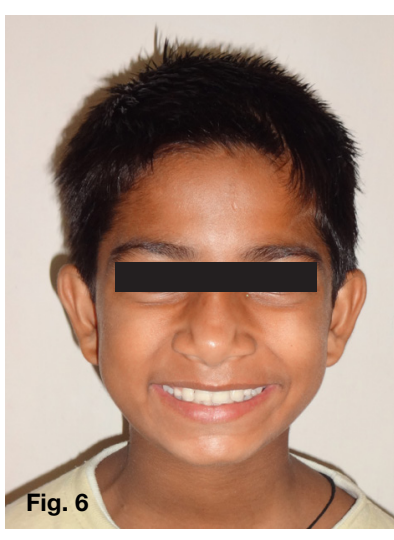

Figure 7. Case 1 - Post-treatment intraoral photographs showing wellaligned incisors.
Fig. $7 \mathrm{C}$

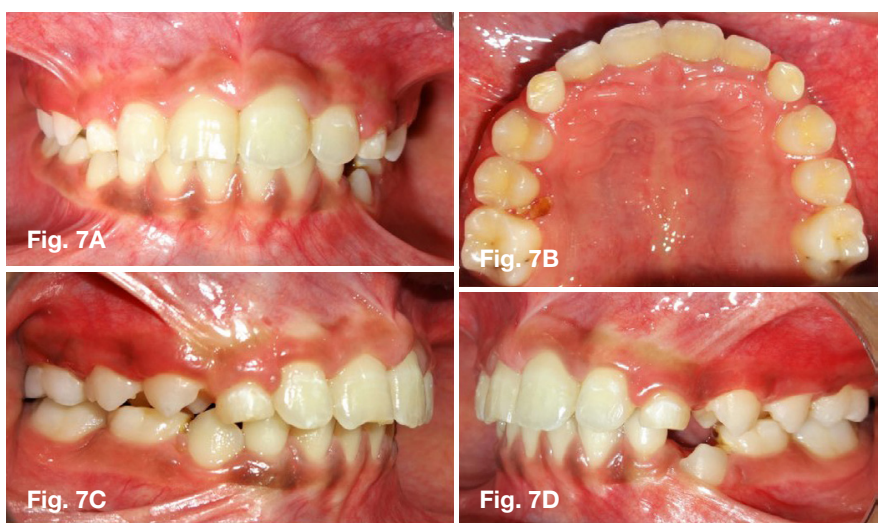

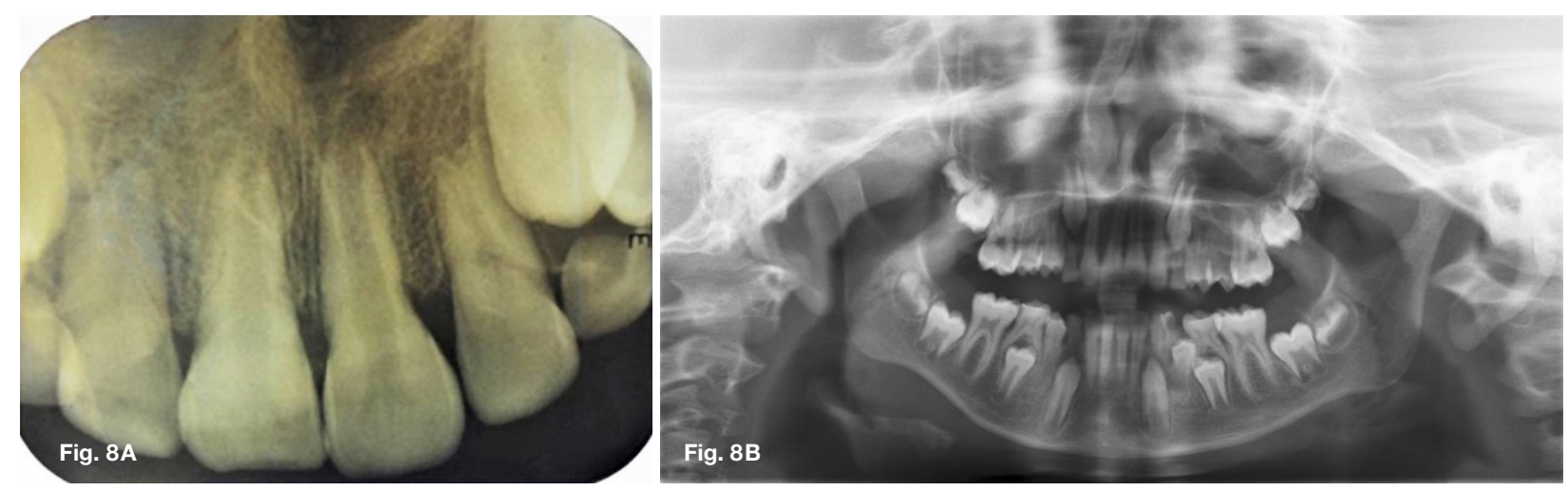

Figure 8. Case 1 - Post treatment radiographs: A. IOPA. B. OPG. 


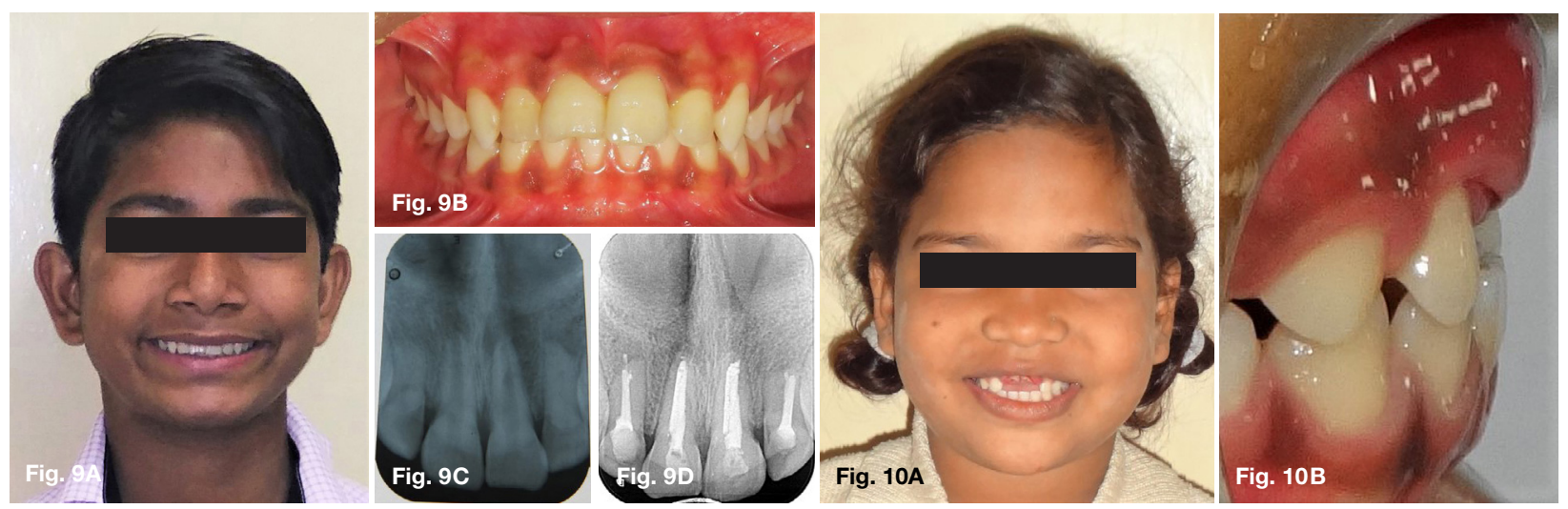

Figure 9. Case 1 - Four year follow up photographs: A. Frontal smile view. B. Intraoral frontal view. C. IOPA pre-endodontic treatment. D. IOPA post

Figure 10. Case 2 - Pretreatment posed smile and intraoral anteroendodontic treatment.
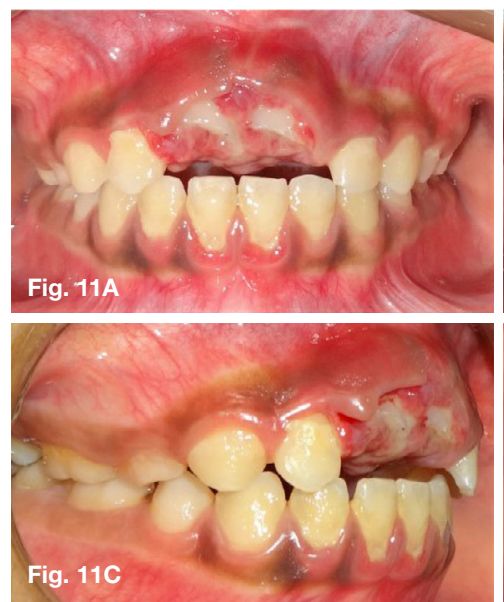

Figure 11. Case 2 - Pre-treatment intraoral photographs showing traumatic intrusion of $11 \& 21$.

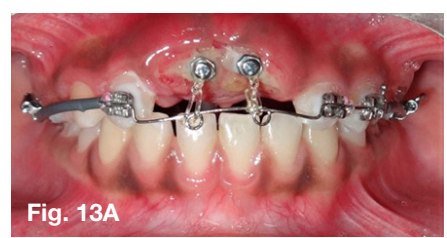

Figure 13. Case 2 - Treatment progress photographs: A. Commencement of traction of 11 and 21 using light force elastomeric chain onto 0.018 " SS base wire. B. Alignment in progress using 0.014" NiTi wire. C. Leveling in progress.
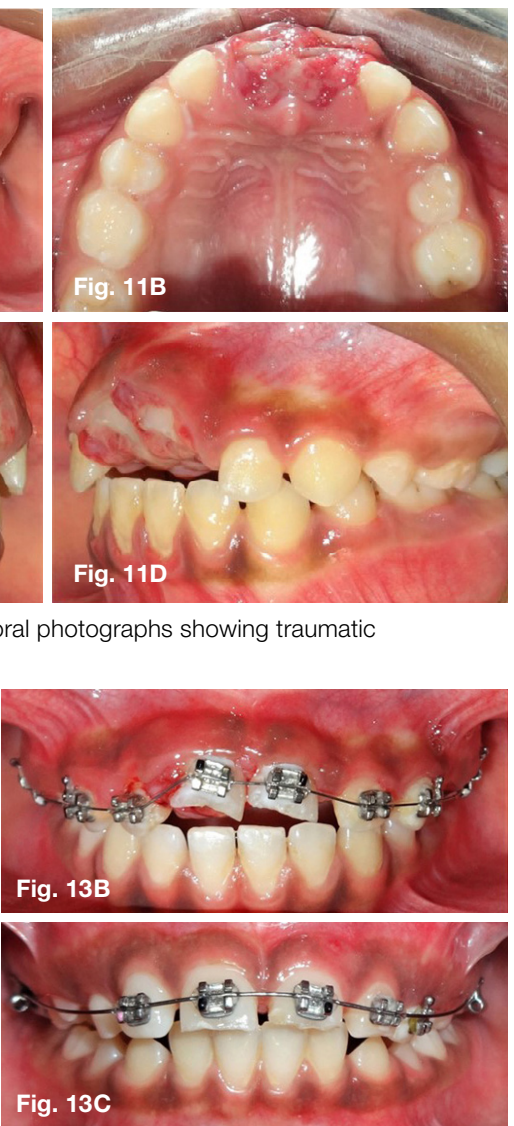
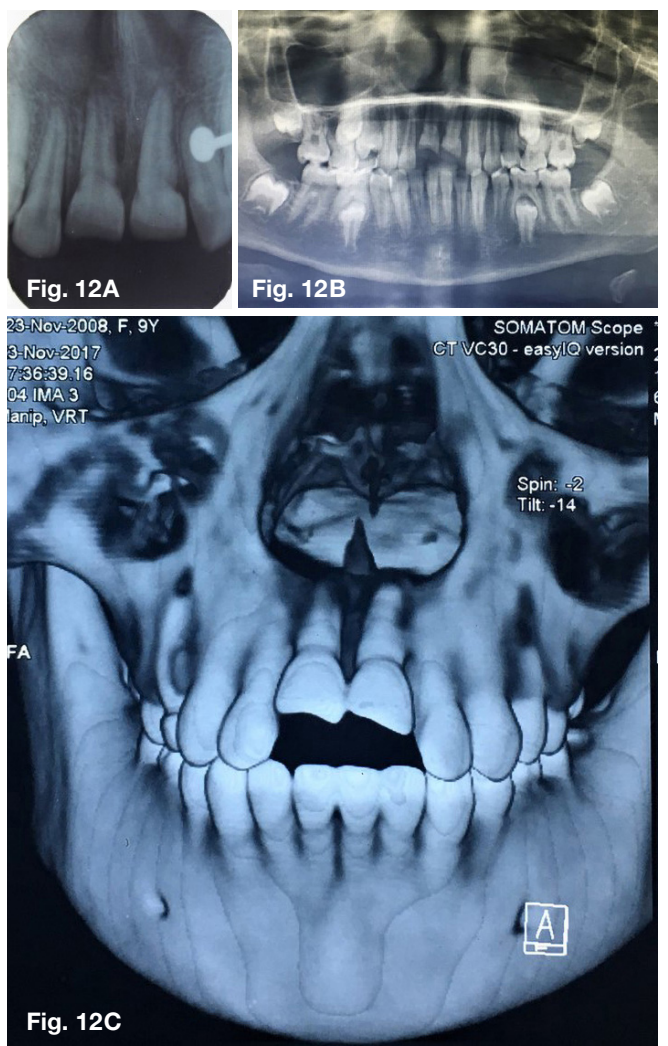

Figure 12. Case 2 - Pre-treatment radiographs: A. IOPA. B. OPG. C. Spiral NCCT showing intrusion of incisors into the floor of nasal cavity.
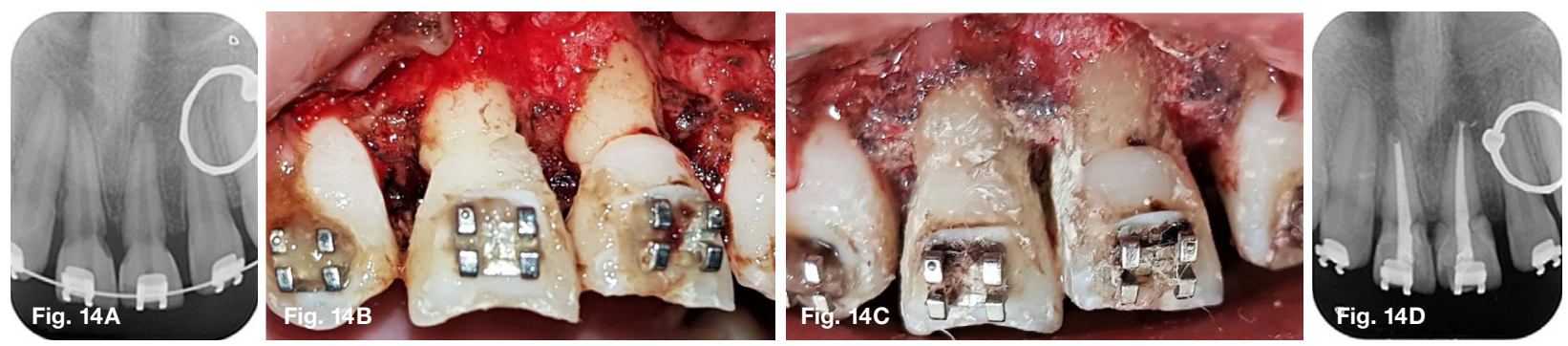

Figure 14. Case 2 - Intraoperative radiographs and photographs: A. IOPA showing resorption areas on mesial and distal surfaces of 11 \& 21 . B. Resorption defects seen on mesial and distal surfaces of 11 \& 21. C. Restoration of defects with biodentine. D. IOPA with biodentine and metapex. 
Case 2

A 9 year old female reported to the Department of Paediatric Dentistry, ESIC Dental College, Delhi with the chief complaint of pain in her upper front teeth (Fig. 10). The patient gave history of fall from bed 2 weeks back resulting in a fracture of her upper front teeth. She complained of persistent headache post injury. Bleeding from oral cavity was reported at the time of trauma which stopped following the application of a pressure pack at a private clinic. Clinical examination revealed inflamed gingiva with respect to $11 \& 21$, while in other areas of oral cavity the gingiva was pale pink in color (Fig. 10, 11).

Traumatic intrusion and Ellis class II fracture was observed in the maxillary left and right central incisors. IOPA $X$-ray and OPG revealed fully mature roots of $11 \& 21$ (Fig. 12A, B). Spiral non-contrast CT scan (Spiral NCCT) confirmed the perforation of nasal floor by the intruded incisors (Fig. 12C).

Orthodontic treatment was initiated using a gingival retraction cord to gain access for bonding lingual buttons on the labial aspects of $11 \& 21$. An 0.018-inch SS wire with 2 helices was used for gradual traction of $11 \& 21$ using light force elastomeric chain (Fig. 13A). Two weeks later, once the labial surface of the intruded incisors was sufficiently visible, MBT brackets were bonded on 11 \& 21 and an improved superelastic 0.014-inch NiTi arch wire was ligated (Fig. 13B).

Root canal treatment was planned for the next sitting. The patient, however, missed an appointment, and when she reported 2 months later, the arch was nearly leveled (Fig. 13C). The IOPA X-ray revealed small areas of external resorption in the cervical area of crown and roots of $11 \& 21$ (Fig. 14A).

Root canal access was gained in 11 \& 21, and calcium hydroxide paste (Metapex; Meta Biomed Ltd, Cheongju, Chungbuk, Korea) was placed in the canals. It was decided to restore the cervical resorption areas and a mucoperiosteal flap was raised and granulation tissue was removed from cervical areas of these teeth (Fig. 14B).

Biodentine was used for restoration of the cervical defects (Fig. 14C). An $0.016 \times 0.022$-inch SS wire was used during the stabilization phase, during which endodontic treatment was completed (Fig. 14D). After 8 months of active treatment, the arch was debonded and a Hawley's retainer was delivered (Fig. 15). Clinical outcome was stable and no further resorption was seen at 2 years follow-up (Fig. 16).

\section{Case 3}

A 10-year old boy reported with history of trauma from a classroom bench in school one week back (Fig. 17). On clinical examination, 22 \& 23 were found to be intruded with 22 showing severe intrusion ( $>7 \mathrm{~mm}$ ) (Fig. 18).

OPG confirmed intrusion and revealed a partially immature root apex of 22 and wide-open root apex of 23 (Fig. 19). It was decided to commence orthodontic traction to correct intrusion after waiting for one more week.
A lingual button was bonded on to the palatal aspect $e$ of 22 as adequate space was not available on the labial surface. A base arch wire of $0.017 \times 0.025$-inch SS was used with ligated overlay wire of 0.014-inch NiTi (Fig. 20A). Once 22 had been sufficiently extruded, an MBT bracket was also bonded on 22 .

Further alignment and leveling progressed with 0.016-inch NiTi wire, $0.016 \times 0.022$-inch NiTi wire and finally with an $0.018 \times 0.025$-inch SS wire (Fig. 20B). Similarly, bonding was done in the lower arch and a normal progression of continuous arch wires was used to level, align, and coordinate the arches.

During the course of orthodontic traction, apical root resorption was observed in 22 (Fig. 20C). Endodontic access was gained in 22 and metapex was placed in the canal (Fig. 20D, 21A). Once continuous lamina dura was discernable, the canal was obturated with guttapercha (Fig. 21B, C). Four years follow-up shows no further root resorption along with good occlusion \& aesthetics (Fig. 22).

\section{DISCUSSION}

In spite of being widely and more closely studied as compared to other injuries, intrusive luxation often poses a management and prognostic challenge to the clinician as, till date, there is lack of consensus on how to best treat an intrusive injury. Various factors that govern the prognosis of intrusive luxation include: the extent of root development, patient's age, degree (severity) of intrusion, tooth type, presence of gingival laceration, number of intruded teeth and associated crown/root fractures.

Root fractures may be infrequently associated with intrusion, with the documented incidence of about $1.4 \% .^{16}$ Presence of an associated root fracture tends to neces sitate additional management such as reduction of the coronal fragment and rigid splinting for a period of 3 months; and/or intra-radicular splints in the form of metal pins in cases of pulp necrosis. ${ }^{17}$ Of all the factors affecting prognosis, severity of intrusion is considered to be the most critical. ${ }^{7,18,19}$ Intrusions up to $3 \mathrm{~mm}$ have been shown to have excellent prognosis, whereas intrusions $>$ than $6 \mathrm{~mm}$ have poor prognosis with greater chances of pulp necrosis and inflammatory root resorption.

Utilization of CT/ CBCT scans with 3-dimensional reformations in such cases aids in exact localization and visualization of the intrusive injury, particularly root fractures, lateral luxation, nasal floor perforation and any associated complications affecting the temporomandibular joint.

In case 1, severe traumatic intrusion (both central incisors intruded $>5 \mathrm{~mm}$ ) with the involvement of multiple teeth was observed. Since the patient reported two weeks after the injury along with an associated complaint of difficulty in breathing, orthodontic repositioning was commenced immediately.

Hence the possibility of formation of a bony bridge of ankylosis following trauma ${ }^{11}$ was avoided and good periodontal healing with adequate bone support was achieved. 


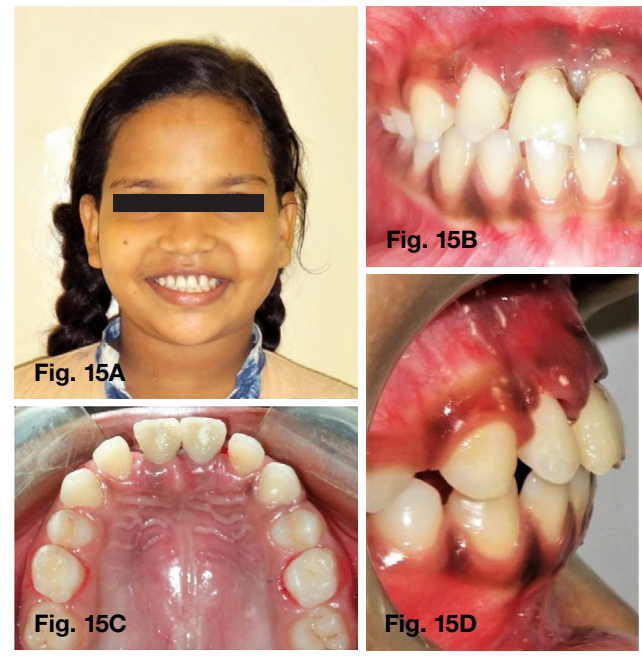

Figure 15. Case 2 - Post-treatment posed smile and intraoral photographs.

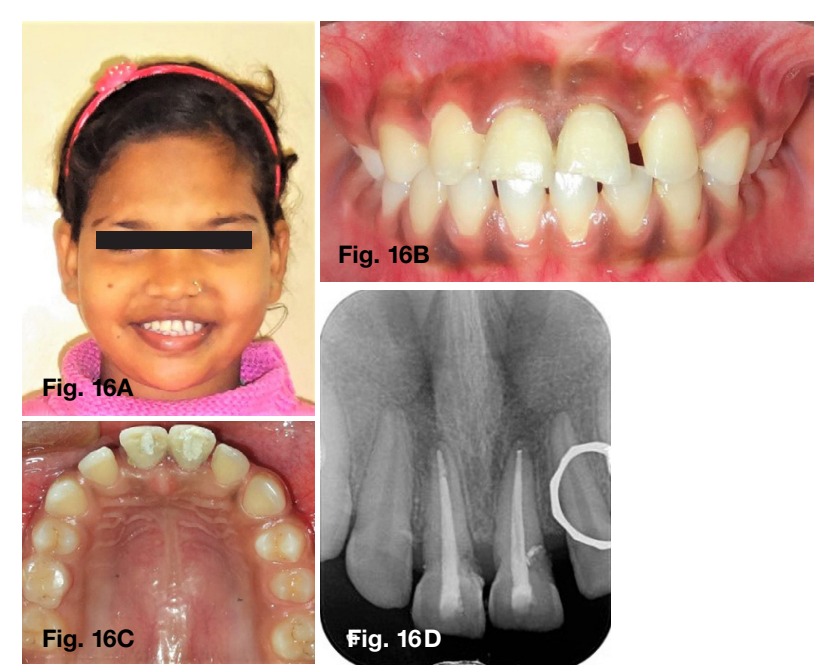

Figure 16. Case 2 - Two year follow up photographs showing stability of achieved results.

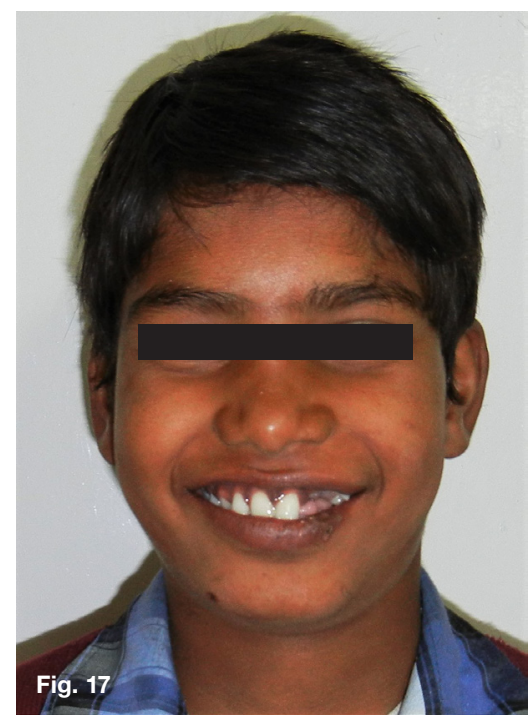

Figure 17. Case 3 - Pretreatment posed smile photograph.
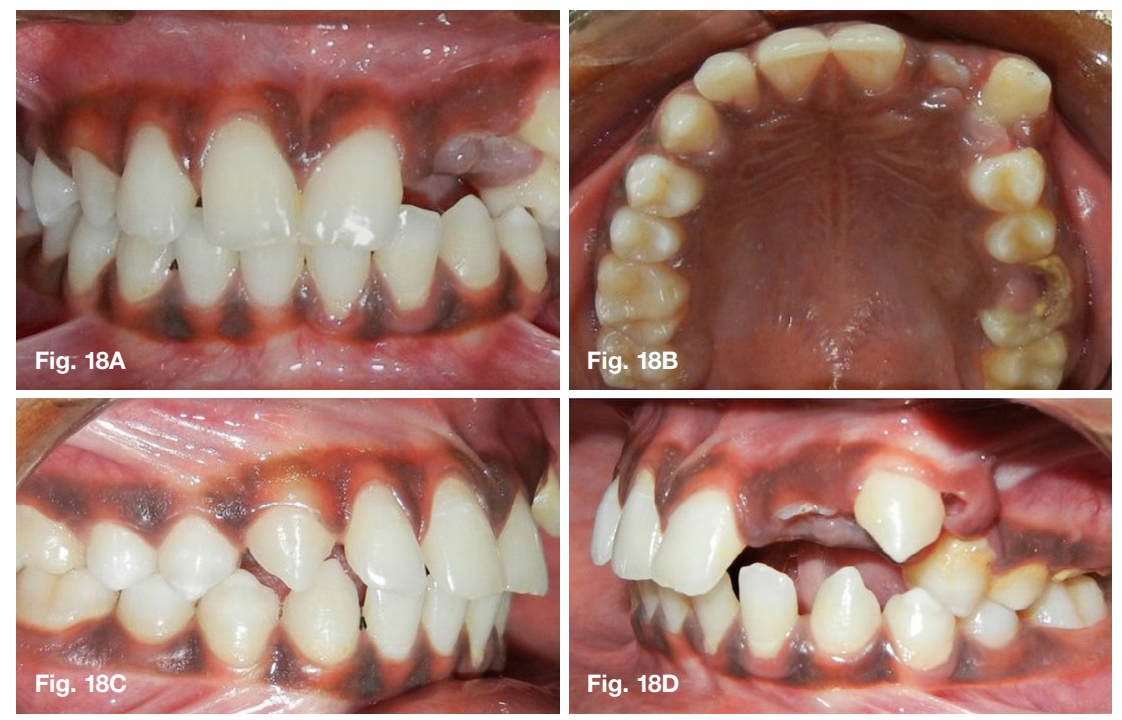

Figure 18. Case 3 - Pretreatment intraoral photographs showing intruded lateral incisor and labially displaced canine.

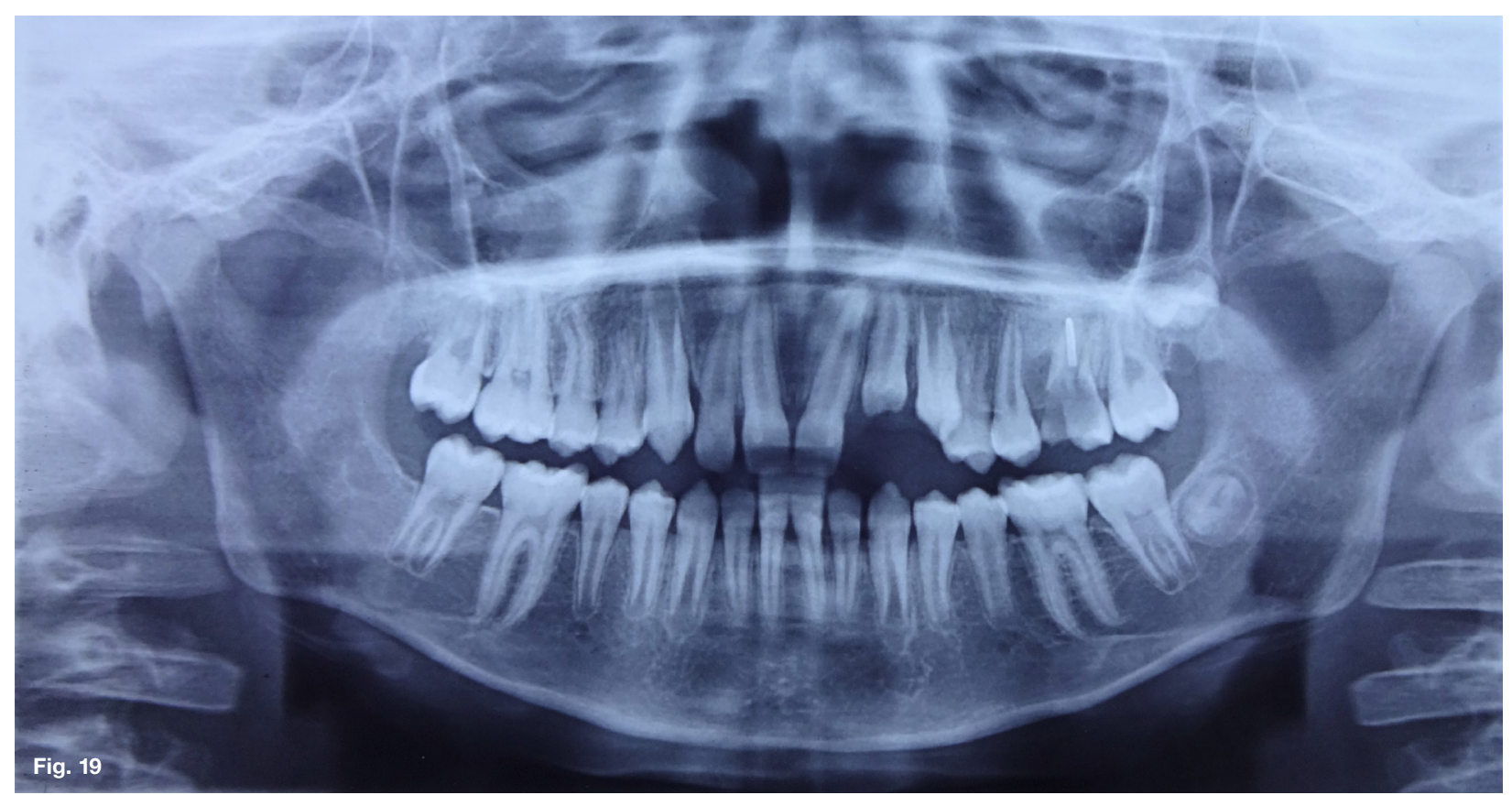

Figure 19. Case 3 - Pretreatment OPG. 
In Case 2, since both the incisors had mature apices, and the extent of intrusion was about $5 \mathrm{~mm}$, treatment was started immediately in accordance with the IADT guidelines. ${ }^{9}$

These two cases demonstrating complete penetration into the nasal cavity (Case $1 \& 2$ ) were thus treated with orthodontic extrusion and good results were obtained.

In Case 3, demonstrating immature apices in 22 and 23, orthodontic extrusion was initiated after waiting for one more week $^{9}$ and continued root formation was observed during the course of orthodontic treatment. However, some apical root resorption was observed in 22 which can be attributed to the higher severity of intrusion $(>7 \mathrm{~mm})$ as compared to 23. As was also observed in Case 1, a severe degree of intrusion may be the cause of root resorption.

Root resorption tends to occur more frequently in teeth with more complete root development. ${ }^{1,20}$ In Case 2, during the course of orthodontic traction, some resorption defects were observed in cervical region of crown and root, which may have developed as a result of damage to the periodontal ligament, orthodontic forces or the severe injury itself.

\section{Endodontic considerations}

Disruption of pulpal blood supply is a major concern in intruded teeth which can lead to pulp necrosis unless revascularization takes place. A strong association has been reported between the width of apical foramen and the chance of revascularization. ${ }^{1,21}$ Hence no endodontic treatment was performed in case $1 \& 3$. However, once root resorption was observed in 22 of Case 3 and root resorption with periapical pathology in Case 1, the endodontic treatment was initiated, and further root resorption avoided. Root canal therapy using a temporary filling with calcium hydroxide is recommended ${ }^{9}$ because of its ability to arrest the ongoing resorption process. ${ }^{22}$

In teeth with mature apices, the higher incidence of pulp necrosis following intrusion necessitates earlier removal of pulp to prevent infection and inflammatory root resorption. ${ }^{8}$ Thus endodontic treatment was planned in Case 2 as soon as the access could be gained, but the patient missed an appointment and treatment was thus delayed.

The ideal time of maintenance of calcium hydroxide dressing in the canal is not established in literature. It can be applied for a long term (upto 6 months) to ensure periodontal health prior to final root canal filling. ${ }^{22}$ Ebeleseder et al. ${ }^{20}$ support a period of 6-9 months while de Alencar et al. ${ }^{18}$ suggest its maintenance till PDL is re-established and intact lamina dura is seen. Calcium hydroxide should be changed periodically. ${ }^{18}$ Once radiographically intact lamina dura was observed in present cases, teeth were obturated with gutta percha.

\section{Orthodontic considerations}

Orthodontic management of intruded teeth using extremely light forces, as performed in above cases, facilitates more biological repositioning as compared to surgical re- positioning. Use of self-etch primer instead of the traditional method of acid etch, wash and bonding, reduces the necessary steps and time required for bonding, thereby making it easier to maintain a blood free zone for placement of brackets.

Self-ligating brackets may be an alternative option as these brackets can be opened or closed gently without creating additional stresses on the teeth, thus reducing the patient's discomfort. In addition, use of improved superelastic NiTi wires provide light consistent forces and allows easy displacement into brackets. ${ }^{23}$ During alignment of severely intruded teeth, placement of superelastic NiTi wire piggyback over a rigid rectangular stainless-steel base wire helps prevent any arch deformation due to reactionary forces. More so, adherence to simple biomechanical principles is crucial for securing acceptable treatment outcomes.

\section{CONCLUSION}

Interdisciplinary approach involving a combination of appropriate orthodontic mechanics and endodontic treatment helped achieve clinically esthetic and functionally acceptable outcomes in the above-mentioned cases. The guidelines available in literature should be followed but with the provision to individualize the treatment plan as per the requirement of each particular case.

\section{Conflict of interest}

There is no conflict of interest.

\section{References}

1. Andreasen JO, Bakland LK, Andreasen FM. Traumatic intrusion of permanent teeth. Part 2. A clinical study of the effect of preinjury and injury factors, such as sex, age, stage of root development, tooth location, and extent of injury including number of intruded teeth on 140 intruded permanent teeth. Dent Traumatol. 2006; 22: 90-8.

2. Omar S, Freccia WF, Retamozo B, Bakland LK. Traumatically intruded permanent teeth: Three case reports and a review of current recommendations. J Calif Dent Assoc. 2017; 45(5): 235-43.

3. Carvalho V, Jacomo DR, Campos V. Frequency of intrusive luxation in deciduous teeth and its effects. Dent Traumatol 2010; 26(4): 304-7.

4. Andreasen JO, Bakland LK, Andreasen FM. Traumatic intrusion of permanent teeth. Part 3. A clinical study of the effect of treatment variables such as treatment delay, method of repositioning, type of splint, length of splinting and antibiotics on 140 teeth. Dent Traumatol. 2006; 22: 99-111.

5. Al-Badri S, Kinirons M, Cole BOI, Welbury RR. Factors affecting resorption in traumatically intruded permanent incisors in children. Dent Traumatol. 2002; 18: 73-6.

6. Kinirons MJ. Treatment of traumatically intruded permanent incisor teeth in children, UK National clinical guidelines in Pediatric Dentistry. Int J Pediatr Dent. 1998; 8: 165-8.

7. Humphrey JM, Kenny DJ, Barrett EJ. Clinical outcomes for permanent incisor luxations in a pediatric population. I Intrusions. Dent Traumatol. 2003; 19: 266-73.

8. Stewart C, Dawson M, Shafi I, Kinirons M, Welbury R. A study of the management of 55 traumatically intruded permanent incisor teeth in children. Eur Archives Pediatr Dent. 2009; 10(1): $25-8$. 

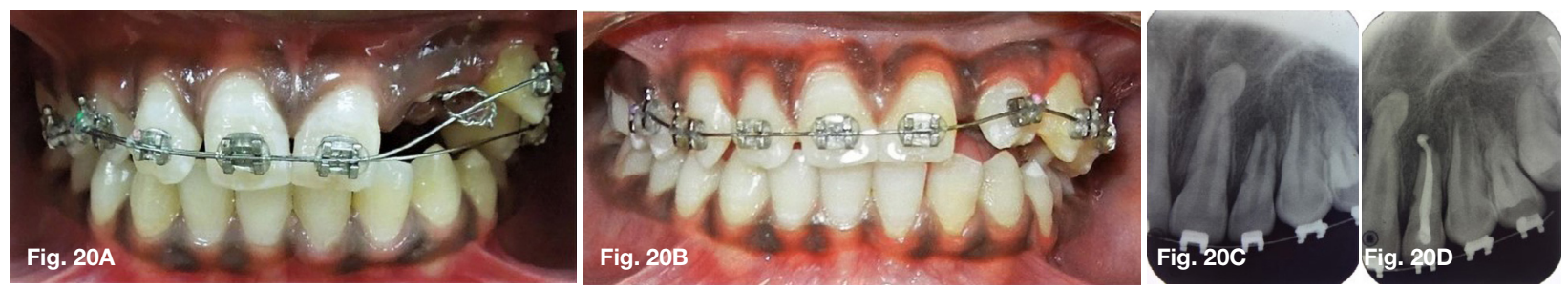

Figure 20. Case 3 - Mid treatment photographs: A. Traction of 22 and 23 using superelastic 0.014 " Niti wire.

B. Progression of alignment and leveling. C. IOPA showing root resorption in 22. D. IOPA with metapex obturation in 22.
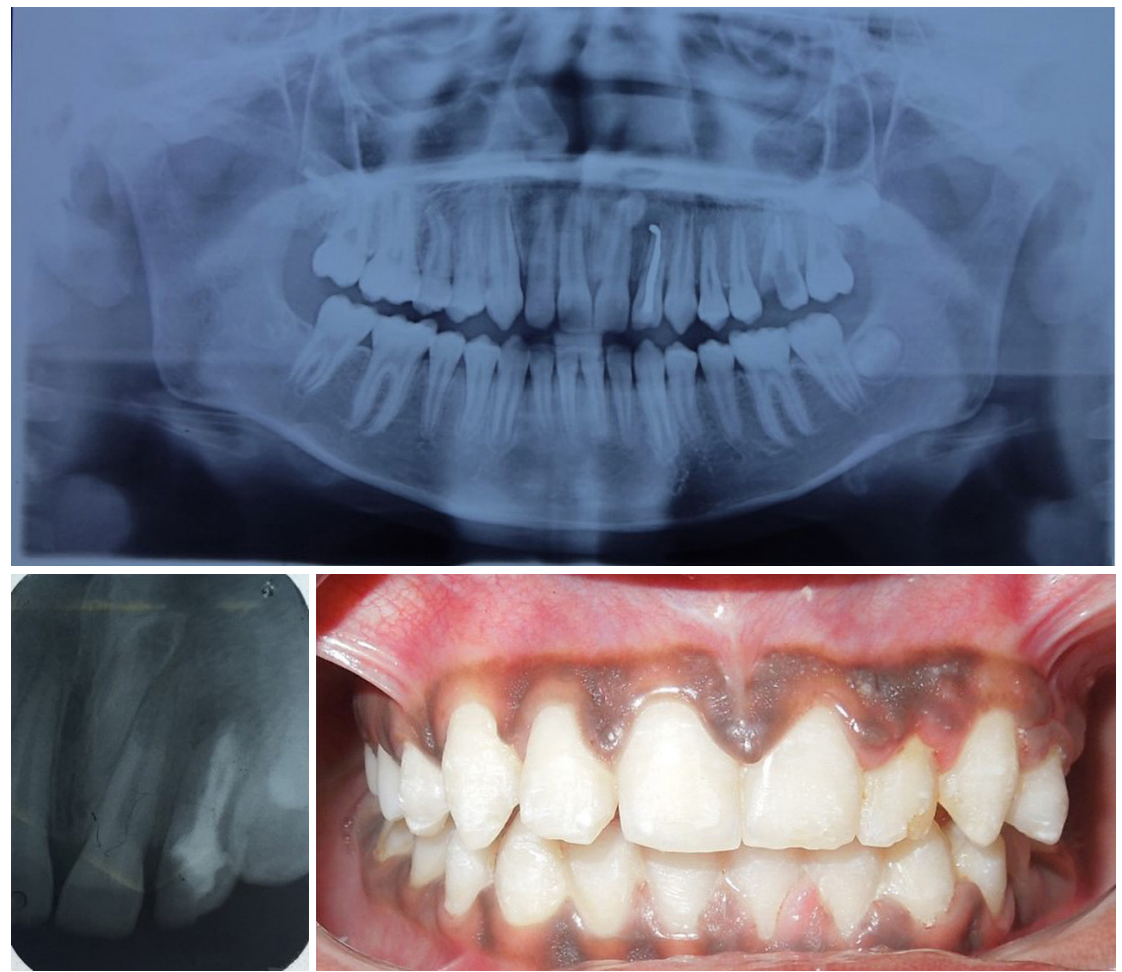

Figure 21. Case 3 - Immediate posttreatment radiographs and photograph

A. OPG. B. Post gutta-percha obturation IOPA. C. Intraoral frontal view.

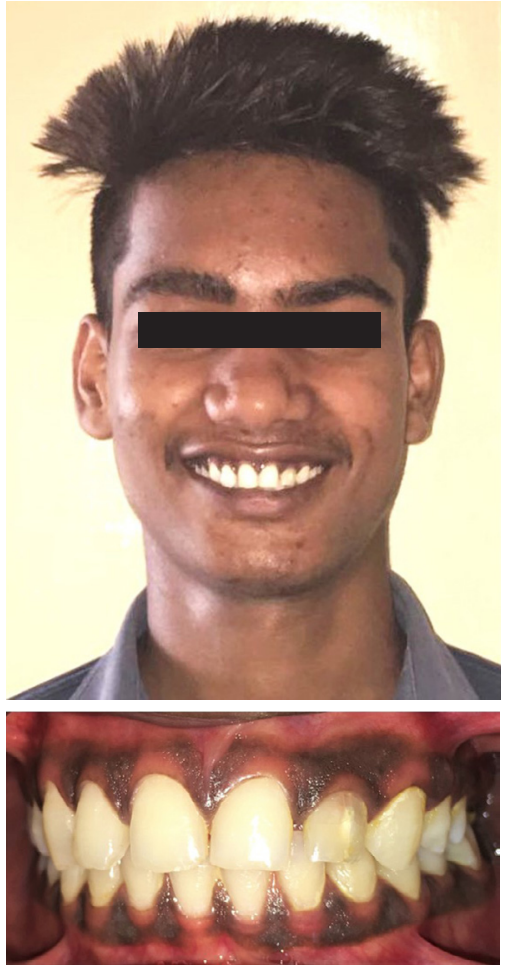

Figure 22. Case 3-4 - year follow-up depicting well-maintained stable results.
9. DiAngelis AJ, Andreasen JO, Ebelesesder KA, Kenny DJ, Trope M, Sigurdsson A, et al. International Association of Dental Traumatology guidelines for the management of traumatic dental injuries: 1. Fractures and luxations of permanent teeth. Dent Traumatol. 2012; 28: 2-12.

10. Calasans-Maia JA, Calasans-Maia MD, Matta ENR, Ruellas ACO. Orthodontic movement in traumatically intruded teeth: a case report. Dent Traumatol. 2003; 19: 292-5.

11. Turley PK, Crawford LB, Carrington KW. Traumatically intruded teeth. Angle Orthod 1987; 57(3): 234-44

12. Andreasen FM, Vestergaard PB. Prognosis of luxated permanent teeth- the development of pulp necrosis. Endod Dent Traumatol. 1985; 1: $205-20$.

13. AlKhalifa JD, AIAzemi AA. Intrusive luxation of permanent teeth: A systemic review of factors important for treatment decision making. Dent Traumatol. 2014; 30: 169-75.

14. Chaushu S, Shapira J, Heling I, Becker A. Emergency orthodontic treatment after the traumatic intrusive luxation of maxillary incisors. Am J Orthod Dentofacial Orthop. 2004; 126(2): 162-72.

15. Andreasen FM, Zhijie Y, Thomson BL. Relationship between pulp dimension and development of pulp necrosis after luxation injuries in the permanent dentition. Endod Dent Traumatol. 1986; 2: 90-8.

16. Andreasen JO, Bakland LK, Matras RC, Andreasen FM. Traumatic intrusion of permanent teeth. Part 1. An epidemiological study of 216 intruded permanent teeth. Dent Traumatol. 2006; 22: 83-9.
17. Seddon RP. Concomitant intrusive luxation and root fracture of a central incisor - report of a case. Endod Dent Traumatol. 1997; 13: 99-102.

18. de Alencar AH, Lustosa-Pereira A, de Sousa HA, Figueiredo JH. Intrusive luxation a case report. Dent Traumatol 2007; 23: 307-12.

19. Chacko V, Pradhan M. Management of traumatically intruded young permanent tooth with 40-month follow-up. Austr Dent J. 2014; 59: 240-4.

20. Ebeleseder KA, Santier G, Glockner K, Hulla H, Pertl C, Quenhenberger F. An analysis of 58 traumatically intruded and surgically extruded permanent teeth. Endod Dent Traumatol. 2000; 16: 34-9.

21. Andreasen FM, Yu Z, Thomsen BI. The relationship between pulpal dimensions and the development pulp necrosis after luxation injuries in the permanent dentition. Endod Dent Traumatol. 1996; 2: 90-8.

22. Ingle J, Bakland LK, Baumgartner JC. Endodontic considerations in dental trauma in Ingle's Endodontics, $6^{\text {th }}$ Edition, BC Decker Inc, Hamilton: 2008, 1330-57.

23. Fields HW \& Christensen JR. Orthodontic procedures after trauma. J Endod. 2013; 39(3S): S78-S87. 